\title{
Liquid chromatographic enantioseparation of racemic beta-blockers via synthesis of diastereomeric amides and (S)-levofloxacin esters as chiral derivatizing agents
}

Ravi Bhushan ( $\nabla$ rbushfcy54@gmail.com )

Bhushan's Lab

Shiv Alwera

Chemistry Deptt, IITRoorkee

\section{Method Article}

Keywords: Enantioseparation; Beta-blockers; Diastereomeric amides; (S)-levofloxacin; HPLC

Posted Date: January 2nd, 2018

DOI: https://doi.org/10.1038/protex.2017.150

License: (c) (1) This work is licensed under a Creative Commons Attribution 4.0 International License. Read Full License 


\section{Abstract}

An effective and simple protocol is described that successfully leads to liquid chromatographic enantioseparation of racemic beta-blockers by derivatization approach \(with an example established with $\backslash(\mathrm{RS})$-metoprolol, and verified by using $\backslash(\mathrm{RS})$-atenolol). The chiral derivatizing reagents $\backslash(\mathrm{CDRs})$ were synthesised using $\backslash(\mathrm{S})$-levofloxacin as the chiral moiety. The effectiveness of this protocol is not limited to enantioseparation but also to determine absolute configuration of diastereomers. The protocol describes $\backslash(\mathrm{i})$ synthesis of CDRs by reaction of $\backslash(\mathrm{S})$-levofloxacin with $\mathrm{N}$-hydroxysuccinimide and $\mathrm{N}$ hydroxybenzotriazole in presence of coupling reagent dicyclohexylcarbodiimide, \(ii) synthesis of diastereomers of racemic beta-blockers under microwave irradiation, $\backslash$ (iii) separation of diastereomers by HPLC and open column chromatography, and \(iv) determination of absolute configuration of diastereomers. The $\backslash(S)$-Lfx based CDRs provide very low limit of detection $\backslash(L O D)$ and limit of quantitation $\backslash(\mathrm{LOQ})$; they can be successfully used in trace analysis of several other racemic compounds containing amino group $\backslash$ (e.g., beta-blockers, amino acids etc).

\section{Introduction}

INTRODUCTION With the thought provoking statement by E. J. Ariëns \(ref. 1) in 1984 that the commonly used racemates were drugs with $50 \%$ contamination there was triggered a debate among pharmacologists and medicinal chemists, it alerted the drug regulators too. The most infamous example of an enantiomeric drug having unwanted side effects in the background was that of thalidomide $\backslash$ (ref. 2). The USFDA announced the policy statement in 1992 restricting the marketing of racemic drugs $\backslash$ (ref. 3). Later in 1996, European Federation of Pharmaceutical Industries and Associations \(EFPIA), US FDA, Pharmaceutical Research and Manufacturers of America \(PhRMA) and Japan Pharmaceutical Manufacturers Association \(JPMA), under the aegis of International Conference on Harmonization \ (ICH) produced a comprehensive set of guidelines for registration of new chiral pharmaceuticals $\backslash$ (ref. 4). These guidelines require pharmaceutical companies to demonstrate stereospecific fate of both the enantiomers in the body including the necessary stereoselective analytical methods of chiral drugs before their introduction into the market and during industrial manufacture. Thus, the development of simple methods for enantioseparation and control of enantiomeric purity for chiral drugs acquires a great significance to facilitate an accurate evaluation of the risks posed by them to human health. The establishment of reliable analytical methods for determination of enantiomers has always been increasing in the fields of chromatography, pharmacology, medicine, asymmetric synthesis, mechanistic studies, extra-terrestrial chemistry, life sciences etc. And, still separation of enantiomers and determination of their purity is challenging and important. Both direct and indirect approaches of enantioseparation \(using LC) have their own advantages and limitations depending upon the source and amount of sample available, chemical structure of the analyte and the ease of availability of laboratory facilities. A large number of papers reporting on the development and application of enantiomeric separations via indirect approach reflect the importance of covalent chiral derivatization in the solution of practical problems in pharmaceutical and biomedical analysis. The primary aim of derivatization in 
enantioseparation is the formation of easy to separate diastereomeric derivatives and at the same time to improve the detectability by introducing chromophoric or fluorophoric groups into enantiomeric molecules. Inspite of availability of different types of detectors $\backslash$ (particularly, in HPLC) UV remains the method of choice for simplicity and cost considerations. Separation of diastereomeric pair via indirect technique is generally simpler to perform and often has better resolution than that obtained with a direct method because chromatographic conditions are much easily optimized and the chiral derivatizing reagents $\backslash(\mathrm{CDRs})$ can provide highly sensitive detector response requiring only an achiral column. The indirect approach must fulfil the following requirements, $\backslash(i)$ the enantiomer molecule and the CDR must possess an easily derivatizable and compatible functional group, $\backslash$ (ii) the CDRs and the diastereomers should be stable, \(iii) the enantiomeric purity of the chiral reagent must be very high or its purity should be known, $\backslash$ (iv) the derivatization reaction should be fast and complete, and, if not so, the reaction rates of two enantiomers must be kinetically equal, and, \(iv) the reaction conditions must be moderate to avoid any racemization of the analyte during the reaction $\backslash$ (ref. 5). Separation via diastereomer formation is usually improved when bulky groups are attached to the stereogenic centre and when the stereogenic centres of both the reagent and the analyte are in close proximity in the resulting diastereomer. Introduction of a chromophore enhances detection \(say, for HPLC separation). Performance of HPLC enantioseparation would thus depend upon the chemical nature of the CDR acting as the reagent tagged to enantiomers, selection of organic modifiers for their polarity, and the adjustment of buffer $\mathrm{pH}$, and concentration. With the above mentioned background, several CDRs have been synthesised and used for enantioseparation of a variety of pharmaceuticals, marketed as racemic mixtures, at this laboratory $\backslash$ (refs. 5-13). These included CDRs having cyanuric chloride or DFDNB or $\backslash(S)$-Naproxen $\backslash(N p x)$ as the chromophoric moiety and were suitable for enantioseparation of pharmaceutically important compounds containing amino group. There have appeared a few review articles on use of CDRs based on DFDNB for HPLC enantioresolution of DL-amino acids, particularly $\backslash$ (refs. 14-16). The diastereomers prepared with DFDNB based CDRs had a very similar absorption spectrum characterized by a $\lambda$-max at $340 \mathrm{~nm}$ but there remains a drawback for DFDNB based derivatives that a gradual change occurs as a result of a photochemical decomposition of the absorbing chromophore, if the solutions are not kept in dark. Unstable derivatives, poor detection of certain derivatives, or lack of quantitative yield of the reaction were the inherent limitations in using other CDRs. The CDRs developed from \(S)-Npx had either amide bond or ester linkage or anhydride. In our laboratory, benzotriazole activated naproxen \(Nap-Btz) was synhesized by an improved, simple and safe method under mild conditions of stirring at room temperature for $2.5 \mathrm{~h}$ using DCC/DMAP coupling reagent $\backslash$ (ref. 17) in contrast to its synthesis in $4 \mathrm{hr}$ using hazardous thionyl chloride by Katritzky et al. \(ref. 18). Success of enantioseparation of several racemic pharmaceuticals using $\backslash(\mathrm{S})$-Npx based CDRs led us to choose $\backslash(\mathrm{S})$-levofloxacin $\backslash(\mathrm{Lfx} ; \mathrm{Fig} .1)$, as the chiral moiety, to

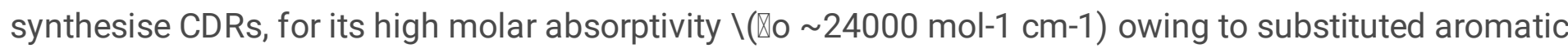
residue and the carboxylic group and its availability in low price as pure $\backslash(S)$-enantiomer. This protocol reports validated enantioseparation of $\backslash(R S)$-Metoprolol $\backslash($ Mel, selected as the analyte from among the common $\beta$-blockers marketed as a racemate) by HPLC using CDRs based on \(S)-levofloxacin, synthesized for this purpose. Here we have also shown that the protocol is successfully applicable to 
enantioseparation of $\backslash(\mathrm{RS})$-atenolol. The methodology could be applied to many other racemic pharmaceuticals containing an amino functional group.

\section{Reagents}

REAGENTS • N-hydroxysuccinimide $\backslash(98 \%$; Sigma Aldrich, CAS no.6066-82-6) $\backslash$ ! CAUTION Being slightly acidic, it is an irritant to skin, eyes and mucous membranes. - N-Hydroxybenzotriazole $\backslash(98 \%$; Rankem, Gurgaon, Haryana, India, CAS no. 2592-95-2) \! CAUTION Risk of explosion if heated under confinement • Dicyclohexylcarbodiimide \(DCC) \(99\%; Sigma-Aldrich, CAS no.538-75-0) \! CAUTION DCC is a potent allergen and a sensitizer, often causing skin rashes. $-\backslash($ RS)-Atenolol $\backslash(98 \%$; Sigma-Aldrich, CAS no.2912268-7) • \(RS)-Metoprolol \(98\%; Sigma-Aldrich, CAS no. 56392-17-7) • Levofloxacin as Levoflox-500 tablets $\backslash$ (Cipla, Mumbai, India) Ten Levoflox tablets, each containing $500 \mathrm{mg}$ of Lfx, after removing coating of red iron oxide and titanium dioxide, were grounded to a fine powder and extracted with $50 \mathrm{~mL}$ $\mathrm{MeOH}$ by sonication at $25^{\circ} \mathrm{C}$. The solution was filtered through Whatman paper $\backslash(8 \mu \mathrm{m}$ pore). The same procedure was repeated twice with the residue. The combined filtrate was concentrated in vacuum and kept at $4{ }^{\circ} \mathrm{C}$ until crystals appeared. The sample was further purified by recrystallization with $\mathrm{CHCl} 3-$ $\mathrm{MeOH}$. The sample was preserved in tightly closed container, protected from light. $\cdot \mathrm{NaHCO} \backslash(99 \%$; Thomas Baker, Mumbai, India, CAS no. 497-19-8) • Triethylamine \(TEA) \(99\%; Rankam, Gurgaon, Haryana, India, CAS no. 121-44-8), It is a colourless volatile liquid with a strong fishy odour. $\cdot 0-$ Phosphoric acid $\backslash(85 \%$; Thomas Baker, Mumbai, India, CAS no. 7664-38-2), \! CAUTION it is corrosive. • Silica gel 60-120 mesh \(for open column) \(SISCO Research Laboratories, Mumbai, India, Batch no. T/827881). • Ethyl acetate $\backslash(99 \%$; Thomas Baker, Mumbai, India, CAS no. 141-78-6), \! CAUTION Overexposure to ethyl acetate may cause irritation of the eyes, nose, \& throat. • Dichloro methane $\backslash(\mathrm{DCM})$ $\backslash(99 \%$; Rankem, Gurgaon, Haryana, India, CAS no. 75-09-2), \! CAUTION the Scientific Committee on Occupational Exposure Limit Values $\backslash(\mathrm{SCOEL})$ recommends for DCM an occupational exposure limit $\backslash(8$ $\mathrm{h}$ time-weighted average) of $100 \mathrm{ppm}$ and a short-term exposure limit $\backslash(15 \mathrm{~min})$ of $200 \mathrm{ppm}$. Chloroform $\backslash(\mathrm{CHCl} 3) \backslash(99 \%$; Molychem, Mumbai, India, CAS no. 67-66-3). \! CAUTION Accidental splashing into the eyes has caused irritation. Prolonged dermal exposure can result in the development of sores. - Ethanol $\backslash$ (EtOH) \(99\%; Merck, CAS no. 64-17-5) • Tetra hydro furan $\backslash(\mathrm{THF}) \backslash(99 \%$; Rankem, Gurgaon, Haryana, India, CAS no. 109-99-9), \! CAUTION It penetrates the skin causing rapid dehydration. THF readily dissolves latex and is typically handled with nitrile or neoprene rubber gloves. It is highly flammable. • Acetonitrile $\backslash(\mathrm{MeCN}) \backslash(99 \%$; Merck, CAS no. 75-05-8) • Methanol \(MeOH) $\backslash(99 \%$; Merck, CAS no. 67-56-1).

\section{Equipment}

EQUIPMENT • HPLC system \(LC-20AD, Shimadzu, Kyoto, Japan) consisted of a DGU-20A5 on-line degasser unit, low-pressure gradient unit, low pressure mixing type gradient, parallel double plunger pump, high pressure mixer, SPD-M20A diode array detector, SPD-20A/20AV \(UV-VIS Detector), CTO-20AC column oven and LC solution and DAO \(data access objects) 3.5 operating software. $\cdot$ LiChrospher C18 column $\backslash(L$ x I.D. $25 \mathrm{~cm} \times 4.6 \mathrm{~mm}, 5 \mu \mathrm{m}$ particle size $)$ from Merck $\backslash($ Darmstadt, Germany). $\cdot$ Microwave- 
Multiwave $3000 \backslash(800$ W, Perkin-Elmer, Shelton, CT, USA) • pH meter Cyberscan $510 \backslash($ Singapore $) \cdot$ Milli-Q system of Millipore $\backslash($ Bedford, MA, USA) to obtain purified water $\backslash(18.2 \mathrm{M} \Omega \mathrm{cm} 3)$ from double distilled water $\cdot$ FT-IR Spectrometer $\backslash($ Nicolet-6700, Thermo Scientific, USA) • Elemental Analyzer $\backslash($ Vario EL III, Hanau, Germany) • NMR spectrometer $400 \mathrm{MHz} \backslash($ JEOL Inc., Peabody, USA) • UV spectra were recorded in $\mathrm{MeOH} \backslash$ (using Shimadzu, UV-2450 Spectrophotometer). $\cdot$ Rotary evaporator $\cdot$ Magnetic stirrer with thermal and speed controller $\backslash$ (REMI Instruments, Mumbai, India) • Teflon-coated magnetic stir bars 300 $\mathrm{mL}$ sample vials $\cdot 1.5$ and $2 \mathrm{~mL}$ vials $\cdot$ Round bottomed flasks $\cdot$ Beakers $\cdot$ Glass columns $\cdot$ Desiccator $\cdot$ Vacuum pump $\cdot$ Centrifugal machine $\cdot 0.45$ - $\mu \mathrm{m}$ pore size filters $\cdot$ Balance for weighing chemicals

\section{Procedure}

PROCEDURE Synthesis of CDR-1, \(levofloxacin-N-hydroxysuccinimide) 1 I Weigh out $360 \mathrm{mg} \backslash(\mathrm{S})$-Lfx and dissolve it in $3 \mathrm{~mL}$ THF \(to obtain a clear solution into a beaker). 2 I Weigh out $115 \mathrm{mg} \mathrm{N}$ hydroxysuccinimide and dissolve it in $3 \mathrm{~mL}$ THF $\backslash$ (to a clear solution into a beaker). 3 I Weight out 226 $\mathrm{mg}$ DCC and dissolve in $5 \mathrm{~mL}$ THF. $\backslash$ ! CAUTION DCC has hygroscopic nature so need to be protected from moisture. ? TROUBLESHOOTING 4 I Fit a $100 \mathrm{~mL}$ round-bottomed flask with rubber septum, load a Tefloncoated magnetic stir bar and generate nitrogen atmosphere inside the flask. $\otimes$ PAUSE POINT Make sure rubber septum tight closed and there is no leakage of nitrogen gas. 5 I Add both the solutions $\backslash$ (from Step-1 and Step-2) into round bottomed flask under nitrogen atmosphere at room temperature. 6 I Switch on the magnetic stirrer. 7 I Add DCC solution drop wise to the mixture in Step 5. 8 I Continue to stir the reaction mixture at room temperature for $3 \mathrm{~h}$. 9 I Filter off the precipitate $\backslash($ so obtained after $3 \mathrm{~h}$ ) and collect the filtrate; evaporate off the filtrate using rotary evaporator to a residue. 10 I Extract the residue with $10 \mathrm{~mL}$ ethyl acetate. 11 I Wash the extract five times with water $\backslash(5 \mathrm{~mL}$, portion each time), five times with brine $\backslash(5 \mathrm{~mL}$, each time) and twice with ice-cold saturated $\mathrm{NaHCO} \backslash(5 \mathrm{~mL}) .12$ I Concentrate the washed extract $\backslash$ (from Step-11) under vacuum and leave overnight to crystallize at room temperature. Recrystallize the product from hot EtOH to yield a pale brown solid product, CDR-1 \(yield: 428mg, 93.4\%). \(The same product, CDR-1, is also obtained by sonicating the reaction mixture of Step 7 for 30 min under nitrogen atmosphere). $\triangle$ PAUSE POINT CDR-1 remains stable for at least 6 months if stored below $4{ }^{\circ} \mathrm{C}$. Synthesis of CDR-2 \(levofloxacin-N-hydroxybenzotriazole) 13 I Prepare CDR-2 in a manner exactly followed for the synthesis of CDR-1 except that N-hydroxybenzotriazole is used in Step $2 \backslash$ (instead of Nhydroxysuccinimide). 14 I The product recrystallized from hot EtOH is pale brown compound; CDR-2 I (yield: $450 \mathrm{mg}, 94.1 \%)$. $($ (The same product, CDR-2, is also obtained by sonicating the reaction mixture for 30 min under nitrogen atmosphere). $\triangle$ PAUSE POINT CDR-2 remains stable for at least 6 months if stored below 4 oC. Synthesis of Diastereomers of $\backslash($ RS)-Mel using CDR-1 and CDR-2 Prepare $1 \mathrm{mM}$ solution of $\backslash$ (RS)-Mel in $0.1 \mathrm{M} \mathrm{NaHCO3}$. Prepare $1 \mathrm{mM}$ solutions of CDR-1 and CDR-2 in acetonitrile. $15 \mathrm{I} \mathrm{In} \mathrm{a} \mathrm{vial}$ containing solution of CDR-1 $\backslash(60 \mu \mathrm{L}, 1 \mathrm{mM})$ and TEA $\backslash(10 \mu \mathrm{L})$, add a solution of $\backslash(\mathrm{RS})$-Mel $\backslash(30 \mu \mathrm{L}, 1 \mathrm{mM}) ; \backslash$ [designated as diastereomeric pair $A \backslash(D s-A)$ ]. 16 I In another vial, containing solution of CDR-2 $\backslash(60 \mu \mathrm{L}$, $1 \mathrm{mM})$ and TEA $\backslash(10 \mu \mathrm{L})$, add a solution of $\backslash(\mathrm{RS})$-Mel $\backslash(30 \mu \mathrm{L}, 1 \mathrm{mM})$; $\backslash$ designated as diastereomeric pair $B$ $\backslash($ Ds-B)]. $\triangle$ PAUSE POINT Reaction required a basic medium $\backslash(\mathrm{pH}$ 9-11) and completion of reaction is monitored on RP-HPLC. 17 I Irradiate the resulting mixtures from steps 15 and 16 under microwave for 
180 seconds using $80 \%$ power $\backslash(800 \mathrm{~W})$. $\otimes$ PAUSE POINT The diastereomers in the reaction mixture are separated by RP-HPLC, using a combination of acetonitrile and triethyl amine buffer $\backslash(\mathrm{pH} 3.4)$ in a ratio of 60:40 $(\mathrm{v} / \mathrm{v})$ as mobile phase. All the solvents are of analytical grade and degassed and filtered before applying to RP-HPLC. ? TROUBLESHOOTING 18 I Diastereomeric pairs $\backslash[A$ and B] synthesized from Steps 15 and 16 are shown in Fig. 2. $\triangle$ PAUSE POINT The chiral moiety of CDR-1 and CDR-2 is the same so the structures of the diastereomers of $\backslash(\mathrm{RS})$-Mel in the pair A and pair B are also the same. Synthesis of diastereomers of $\backslash($ RS)-Mel for preparative separation $\triangle$ PAUSE POINT Since the diastereomers synthesized in Step 15 and 16 are the same only CDR-1 was used for preparative scale synthesis of diastereomers of $\backslash(R S)$-Mel. The optimised conditions of synthesis of diastereomers $\backslash($ Step 17) were scaled up to preparative level. 19 I Weigh out $120 \mathrm{mg}$ racemic $\backslash(\mathrm{RS})$-Mel and prepare a solution in $10 \mathrm{~mL}$ 0.1M NaHCO3. 20 I Weigh out $310 \mathrm{mg}$ CDR-1 and dissolve in $30 \mathrm{~mL}$ acetonitrile. 21 I Add $10 \mathrm{~mL}$ solution of Step 19, $20 \mathrm{~mL}$ solution of Step 20 and $140 \mu \mathrm{L}$ TEA in a $100 \mathrm{~mL}$ vial, mix well and irradiate the mixture under microwave for 180 seconds using $80 \%$ power $\backslash($ i.e., $800 \mathrm{~W}$ ). $\otimes$ PAUSE POINT \(i) TEA is used to maintain pH between 9-11. \(ii) Completion of reaction is confirmed by examining a dilute sample on RPHPLC. Open column chromatography: Packing of column and separation of diastereomers of $\backslash(\mathrm{RS})$-Mel 22 I Pack a glass column $\backslash(2.5 \times 35 \mathrm{~cm})$ with slurry of silica gel in n-hexane. $\otimes$ PAUSE POINT Column must be uniformly packed and remove air bubble, if any, before loading the sample. 23 I Concentrate the reaction mixture $\backslash$ (containing diastereomers) from Step 21 under vacuum and load onto the column $\backslash$ (prepared in Step 22). 24 I Use a mixture of $\mathrm{CH} 3 \mathrm{OH}-\mathrm{CH} 2 \mathrm{Cl} 2 \backslash(9: 1, \mathrm{v} / \mathrm{v})$ to run the column $\backslash($ from Step 22) $\square$ PAUSE POINT The solvent combination is found successful for adequate separation of the two diastereomers. 25 I Collect fractions of about $3 \mathrm{~mL}$ each and examine on RP-HPLC; combine identical ones and concentrate in vacuum. 26 I Allow to crystallize the two sets of the concentrates; yield for first eluting diastereomer is $115 \mathrm{mg} \backslash$ (yield 85\%) and that of the second eluting diastereomer is $110 \mathrm{mg} \backslash$ (yield $80 \%), \backslash($ designated as DsA-1 and DsA-2), respectively.

\section{Timing}

Experimental Approach The carboxylic group of $\backslash(\mathrm{S})$-Lfx was activated by reaction with $\mathrm{N}$ hydroxybenzotriazole because esters of 1-hydroxy benzotriazole are extremely potent acylating agents 19 while $\mathrm{N}$-hydroxysuccinimide esters are highly reactive and yield the desired amide bond $\backslash$ (between amino group of $\backslash(\mathrm{RS})$-Mel and the carbonyl of $\backslash(\mathrm{S})$-Lfx) with expected ease $\backslash($ ref. 20). The exceptional reactivity of the two esters is due to the effect of neighbouring $\mathrm{N}$-atom $\backslash$ (providing anchimeric assistance). Besides being very good nucleophiles, the benzotriazole and succinimidyl moieties serve as very good leaving groups when substituted with amino group containing $\backslash(R S)$-Mel leading to easy formation of diastereomers. Diastereomers were synthesized under mild derivatization conditions with shorter reaction time. Reaction conditions for synthesis of CDRs and diastereomers were optimized. The nucleophilic substitution of the hydroxybenzotriazole or the hydroxysuccinimidyl moiety by the attack of the amino group of the analyte leads to the formation of diastereomeric pair containing amide bond $\backslash$ (which is a rigid structure). The structures of diastereomers drawn on the basis of chemical reaction between $\backslash(\mathrm{RS})$ -

Mel and the CDR having chiral auxiliary with $\backslash(S)$-configuration are shown in Fig.2; these are designated 
as $\backslash(S, S)$-, and $\backslash(S, R)$-diastereomers, respectively, where the first letter $\backslash(S)$ corresponds to the configuration of chiral auxiliary and the other $\backslash(S) /(R)$ corresponds to that of $\backslash(S)$-Mel or $\backslash(R)$-Mel. Analysis The CDRs and diastereomers were characterized by using spectroscopic technique like $1 \mathrm{H}-\mathrm{NMR}$, UV-visible, IR, elemental analysis and HRMS. The chiral purity of CDRs was established as per methods reported earlier from this laboratory21-23. The diastereomers were separated by achiral RP-HPLC as well as by open column chromatography $\backslash$ (for preparative separation in good yield). Separation of diastereomers by RPHPLC was successful using Acetonitrile-TEAP $\backslash(60: 40, v / v)$ as the mobile phase and $\mathrm{CH} 3 \mathrm{OH}-\mathrm{CH} 2 \mathrm{Cl} 2 \backslash(9: 1, \mathrm{v} / \mathrm{v})$ was successful for preparative separation by open column chromatography. The mobile phase ratios were systematically optimized. Because of the structural features of the CDRs $\backslash$ (e.g., based on $\backslash(S)$-Lfx, in the present case), the diastereomers contain increased number of aromatic residues and polar groups which influence interaction with C18 stationary phase during elution and also show enhanced absorption in UV-visible detector. Sections of chromatograms showing separation of diastereomers of $\backslash(\mathrm{RS})$-Mel prepared with CDR-1 and CDR-2 are shown in Fig. 3. Structures of diastereomers $1 \mathrm{H}$ NMR spectra of the purified diastereomers $\backslash$ (separated through open column chromatography) show chemical shift values for the peaks of $-\mathrm{OH}$ signal in the two diastereomers at $\delta$ 2.05 and $\delta 2.27$. The difference in chemical shift $\backslash($ i.e., $\Delta \delta R S$ value of -0.22 ) is large enough for a diagnostic $-\mathrm{OH}$ signal which can be represented as, $\backslash[\Delta \delta \mathrm{RS} \backslash(\mathrm{OH})=\delta S \backslash(\mathrm{OH})-\delta \mathrm{R} \backslash(\mathrm{OH})]$, where $\backslash(\mathrm{R})$ and $\backslash$ (S) descriptors refer to the stereogenic configuration in the Mel moiety. The $\delta$ values $\backslash($ in ppm) of $-\mathrm{OH}$ proton and the $1 \mathrm{H}$ NMR signals corresponding to the asymmetric center in Mel in the $\backslash(S, S)$-, and $\backslash(S, R)$ diastereomers are shown in Supplementary Fig. 1. Further, the lowest energy optimized structures of the diastereomers were developed, using the Gaussian 09 Rev. A.02 program and hybrid density functional B3LYP with 6-31G* basis set $\backslash$ (based on density functional theory), and are shown in Fig.4. The structures clearly show formation of an intramolecular hydrogen bond between the carbonyl group of $\backslash(\mathrm{S})$-Lfx molecule and hydroxyl group of Mel in one of the diastereomers while formation of such an intramolecular hydrogen bond was not possible in the other diastereomer. The formation of $\mathrm{H}$-bonding in one of the diastereomers is considered to be responsible for difference in the chemical shift of the $-\mathrm{OH}$ signal in the $1 \mathrm{H}$ NMR spectra \(Supplementary Fig. 1). The formation of hydrogen bond causes a downfield shift and a difference in the chemical shift of the $-\mathrm{OH}$ protons in the two diastereomers is observed. Thus the formation of hydrogen bond in one of the diastereomers only arises due to specific spatial arrangement. Separation mechanism and elution order It can be observed $\backslash$ (Fig.4) that in $\backslash(S, R)$ diastereomer $\backslash(D s A-2)$ the bulky groups like phenyl \(of Mel) and piperazinyl $\backslash$ (of $L f x$ ) are present on the same side of the planar amide bond $\backslash$ (cis-, type orientation) and this planarity further supports the formation of intramolecular $\mathrm{H}$-bond between the $-\mathrm{OH}$ proton \(in the Mel moiety) and the carbonyl oxygen $\backslash$ (of the Lfx moiety). On the other hand, in $\backslash(S, S)$-diastereomer $\backslash(D s A-1)$, these groups are spatially oriented on the opposite side $\backslash$ (i.e., trans geometry) and there is no intramolecular $\mathrm{H}$-bonding. These differences $\backslash$ (in terms of steric arrangement and the $\mathrm{H}$-bond) cause difference in hydrophobicity which would be expected to result into differential interaction of the diastereomers with the C18 material of the column. The diastereomer with cis orientation is considered to have a stronger interaction with the $\mathrm{C} 18$ column material; these stronger or weaker interactions lead to different retention times of the two diastereomers and their separation. Therefore, the $\backslash(S, R)$-diastereomer $\backslash(D s A-2)$ having cis-type 
orientation would have larger retention time as compared to $\backslash(S, S)$-diastereomer $\backslash(D s A-1)$, having the trans-type arrangement. The three point rule $\backslash$ (ref. 24) proposed for resolution of enantiomers considers $\mathrm{H}$-bond as one of the important factors along with $\pi-\pi$ interactions and steric repulsions, between the CSP and one of the enantiomeric forms to distinguish between the two enantiomeric forms. But in the present case, the stationary phase is achiral and the $\backslash(S)$-Lfx moiety being chiral is responsible for the formation of diastereomers $\backslash$ (for example from CDR-1) and the differential interaction of the diastereomers with the ODS causes separation. Protocol overview The protocol is a successful and simple method for enantioseparation, by derivatization approach, not only on an analytical scale but also on a preparative level. \(S)-Lfx based CDRs are esters in terms of nature of chemical bonding introduced during their synthesis by activating carboxyl group by its reaction with $\mathrm{N}$-hydroxysuccinimide or $\mathrm{N}$ hydroxybenzotriazole in presence of DCC as the coupling reagent. This protocol is focussed on analytical separation of diastereomers of $\backslash(\mathrm{RS})$-Mel by RP HPLC and preparative separation and isolation of diastereomers by open column chromatography. For this purpose, two new CDRs were synthesised using $\backslash(\mathrm{S})$-Lfx as the chiral moiety and microwave assisted synthesis of diastereomers of $\backslash(\mathrm{RS})$-Mel was carried out. Absolute configuration of the diastereomers was established with the help of $1 \mathrm{H}$ NMR \(supported by developing the lowest energy optimized structures of the diastereomers) to ensure the success of diastereomeric synthesis and to establish the reliability of enantioseparation. It becomes desirable because most of the time diastereomer corresponding to pure enantiomer of the analyte is not available while for the enantioseparation investigation to be reliable and to apply the said separation method conveniently to determine enantiomeric purity of the pharmaceutical sample it is desirable to confirm the absolute configuration of diastereomers so separated at the time of optimizing the separation conditions.

\section{Troubleshooting}

? TROUBLESHOOTING Troubleshooting advice can be found in Table 1. $\triangle$ TIMING Steps 1-12, synthesis of CDR-1: 20 h \(Steps 1- 3, 30 min; Steps 4-8, 4h; Steps 9-10, 2h; Step-11-12, 14-15h) Steps 13-14, synthesis of CDR-2: $20 \mathrm{~h} \backslash$ (similar like synthesis of CDR-1) Steps 15-17, synthesis of diastereomers for RP-HPLC: $2 \mathrm{~h} \backslash($ Steps 15-16, 30 min; Steps 19-20, 1:30 h) Steps 19-21, preparative synthesis: $1 \mathrm{~h} \backslash$ (Steps 21-24, 30 min; Steps 25-26, 1:30h) Steps 22-26, open column separation: 9h \(Steps 27-29, 1h; Steps 30$34,8 \mathrm{~h})$

\section{Anticipated Results}

ANTICIPATED RESULTS The $\backslash(S)$-Lfx moiety in the CDRs adds a highly absorbing chromophore that converts $\backslash(\mathrm{RS})$-Mel $\backslash$ (or other amino group containing racemate) into UV active diastereomers. This allows separation of $\backslash(R)$-, and $\backslash(S)$-components of the racemate as diastereomers in the nano range on an achiral column with the inherent rapidity of determination in HPLC. The other advantage of the CDRs is the increased but differential hydrophobicity \(thus increasing $a$ and Rs) of the derivatives. The protocol can be successfully applied for determination and control of enantiomeric purity of $\backslash(\mathrm{RS})$-Mel routinely in industries and R\&D laboratories $\backslash$ (even without resorting to $1 \mathrm{H} N \mathrm{NR}$, and DFT, each time). The 
method can also be applied for detection of trace amount of amino group containing pharmaceuticals which are marketed and administered as racemic mixture. Retention factors $\backslash(k)$, separation factor $\backslash(a)$ and resolution $\backslash(R s)$ were calculated and the separation method was validated for linearity, accuracy, limit of detection \(LOD) and limit of quantification \(LOQ); the details are provided in 'Supplementary' information. Organic synthesis: The analytical data of organic compounds are given below. CDR-1 \ (levofloxacin-N-hydroxysuccinimide). Brown solid, m.p. 117-118 oC Specific rotation= $-92 \bigcirc(\mathrm{c}=0.3$ in $\mathrm{MeOH}$ at 25 C) UV \(294 nm, $\lambda$ max in $\mathrm{MeOH})$ IR $\backslash(\mathrm{KBr}, \mathrm{cm}-1): 3435,2927,2361,1704,1628,1576,1481$, $1305,12451 \mathrm{H}$ NMR $\backslash(400 \mathrm{MHZ}, \mathrm{CDCl} 3)$ delta $1.58 \backslash(\mathrm{d}, 3 \mathrm{H}), 2.29 \backslash(\mathrm{s}, 3 \mathrm{H}) 2.65 \backslash(\mathrm{t}, 4 \mathrm{H}), 2.89 \backslash(\mathrm{s}, 3 \mathrm{H}), 3.36 \backslash$ $(\mathrm{m}, 1 \mathrm{H}), 3.66 \backslash(\mathrm{t}, 4 \mathrm{H}), 4.37-4.52 \backslash(\mathrm{dd}, 2 \mathrm{H},-0-\mathrm{CH} 2-), 7.65 \backslash(\mathrm{d}, 1 \mathrm{H}, \mathrm{Ar}-\mathrm{H}), 8.62 \backslash(\mathrm{s}, 1 \mathrm{H}, \mathrm{Ar}-\mathrm{H}) \mathrm{HRMS} \backslash(\mathrm{m} / \mathrm{z})$ 481.2039 \(\[M+Na]+, 20\%) Analysis \(calculated, found for $\mathrm{C} 22 \mathrm{H} 23 \mathrm{FN} 406), \mathrm{C} \backslash(57.64,57.58) \mathrm{H} \backslash(5.06$, 5.18) $\mathrm{N} \backslash(12.22,12.31)$ CDR-2 $\backslash($ levofloxacin-N-hydroxybenzotriazole). Pale yellow solid, m.p. 138-139 o Specific rotation $=-93$ o $\backslash(\mathrm{c}=0.3 \mathrm{in} \mathrm{MeOH}$ at $25 \mathrm{C}) \mathrm{UV} \backslash(294 \mathrm{~nm}, \lambda \max$ in $\mathrm{MeOH}) \mathrm{IR} \backslash(\mathrm{KBr}, \mathrm{cm}-1) 3328$, 2927, 2851, 1710, 1626, 1574, 1475, 1398, $12451 \mathrm{H}$ NMR $\backslash(400 \mathrm{MHz}, \mathrm{CDCl} 3)$ delta- $1.56 \backslash(\mathrm{d}, 3 \mathrm{H}), 2.29 \backslash(\mathrm{s}$, $3 \mathrm{H}), 2.78 \backslash(\mathrm{s}, 4 \mathrm{H}), 3.22 \backslash(\mathrm{m}, 1 \mathrm{H}), 3.54 \backslash(\mathrm{t}, 4 \mathrm{H}), 4.28-4.40 \backslash(\mathrm{dd}, 2 \mathrm{H}), 7.31 \backslash(\mathrm{m}, 2 \mathrm{H}, \mathrm{Ar}-\mathrm{H}), 7.61 \backslash(\mathrm{d}, 1 \mathrm{H}, \mathrm{Ar}-\mathrm{H})$, $7.65 \backslash(\mathrm{d}, 1 \mathrm{H}, \mathrm{Ar}-\mathrm{H}), 7.78 \backslash(\mathrm{d}, 1 \mathrm{H}, \mathrm{Ar}-\mathrm{H}), 8.59 \backslash(\mathrm{s}, 1 \mathrm{H}, \mathrm{Ar}-\mathrm{H}) \mathrm{HRMS} \backslash(\mathrm{m} / \mathrm{z}) 501.2058 \backslash(\backslash[\mathrm{M}+\mathrm{Na}]+, 25 \%)$ Analysis $\backslash$ (Calculated, found for $\mathrm{C} 24 \mathrm{H} 23 \mathrm{FN6O4}), \mathrm{C} \backslash(60.25,60.12) \mathrm{H} \backslash(4.85,4.74) \mathrm{N} \backslash(17.56,17.68)$; Open Column Chromatography: First eluted diastereomer \(DsA-1) Yellow-brown, m.p. 135-138 oc Specific rotation $=-60$ o $\backslash(\mathrm{c} 0.5 \mathrm{in} \mathrm{MeOH}$ at $25 \mathrm{C}) \mathrm{UV} \backslash(294 \mathrm{~nm}, \lambda \max$ in $\mathrm{MeOH}) \mathrm{IR} \backslash(\mathrm{KBr}, \mathrm{cm}-1)$ : 3300, 2928, 2851, 1709, 1627, 1576, 1444, 1383, 1312, 1244, 1087 1H NMR \(400MHz, CDCl3)delta- \(d, 6H), $1.60 \backslash(\mathrm{d}$, $3 \mathrm{H}), 2.25 \backslash(\mathrm{s}, 1 \mathrm{H}), 2.35 \backslash(\mathrm{s}, 3 \mathrm{H}), 2.54 \backslash(\mathrm{s}, 4 \mathrm{H}), 2.78 \backslash(\mathrm{t}, 2 \mathrm{H}), 2.94 \backslash(\mathrm{m}, 1 \mathrm{H}), 3.12 \backslash(\mathrm{d}, 1 \mathrm{H}), 3.21 \backslash(\mathrm{m}, 1 \mathrm{H}), 3.32$ $\backslash(\mathrm{s}, 3 \mathrm{H}), 3.36-3.41 \backslash(\mathrm{m}, 5 \mathrm{H}), 3.53 \backslash(\mathrm{t}, 2 \mathrm{H}), 3.89-3.99 \backslash(\mathrm{m}, 2 \mathrm{H}), 4.32-4.45 \backslash(\mathrm{m}, 2 \mathrm{H}), 4.50 \backslash(\mathrm{d}, 1 \mathrm{H}), 6.80 \backslash(\mathrm{d}, 2 \mathrm{H}$, Ar-H), $7.09 \backslash(\mathrm{d}, 2 \mathrm{H}, \mathrm{Ar}-\mathrm{H}), 7.68 \backslash(\mathrm{d}, 1 \mathrm{H}, \mathrm{Ar}-\mathrm{H})$ and $8.60 \backslash(\mathrm{s}, 1 \mathrm{H}, \mathrm{Ar}-\mathrm{H}) \mathrm{HRMS} \backslash(\mathrm{m} / \mathrm{z}) 633.3098 \backslash(\backslash[\mathrm{M}+\mathrm{Na}]+$, $30 \%$ ) Analysis $\backslash$ (calculated, found for $\mathrm{C} 33 \mathrm{H} 43 F N 406), C \backslash(64.90,64.74) \mathrm{H} \backslash(7.10,7.02) \mathrm{N} \backslash(9.17,9.20)$ Second eluted diastereomer $\backslash($ DsA-2): Yellow-brown, m.p. 132-136 C Specific rotation $=-38$ o $\backslash(\mathrm{c}=0.5$, $\mathrm{MeOH}$ at $25 \mathrm{C}) \mathrm{UV} \backslash(294 \mathrm{~nm}, \lambda \max$ in $\mathrm{MeOH}) \mathrm{IR} \backslash(\mathrm{KBr}, \mathrm{cm}-1): 3300,2930,2852,1709,1627,1575,1440$, $1383,1316,1244,10891 \mathrm{H} \mathrm{NMR} \backslash(400 \mathrm{MHz}, \mathrm{CDCl})$ delta- $\backslash(\mathrm{d}, 6 \mathrm{H}), 1.59 \backslash(\mathrm{d}, 3 \mathrm{H}), 2.06 \backslash(\mathrm{s}, 1 \mathrm{H}), 2.36 \backslash(\mathrm{s}$, $3 \mathrm{H}), 2.54 \backslash(\mathrm{s}, 4 \mathrm{H}), 2.75 \backslash(\mathrm{t}, 2 \mathrm{H}), 2.92 \backslash(\mathrm{m}, 1 \mathrm{H}), 3.11 \backslash(\mathrm{d}, 1 \mathrm{H}), 3.20 \backslash(\mathrm{m}, 1 \mathrm{H}), 3.30 \backslash(\mathrm{s}, 3 \mathrm{H}), 3.35-3.42 \backslash(\mathrm{m}$, $5 \mathrm{H}), 3.53 \backslash(\mathrm{t}, 2 \mathrm{H}), 3.89-3.97 \backslash(\mathrm{m}, 2 \mathrm{H}), 4.31-4.43 \backslash(\mathrm{m}, 2 \mathrm{H}), 4.48 \backslash(\mathrm{d}, 1 \mathrm{H}), 6.81 \backslash(\mathrm{d}, 2 \mathrm{H}, \mathrm{Ar}-\mathrm{H}), 7.09 \backslash(\mathrm{d}, 2 \mathrm{H}, \mathrm{Ar}-$ $\mathrm{H}), 7.68 \backslash(\mathrm{d}, 1 \mathrm{H}, \mathrm{Ar}-\mathrm{H})$ and $8.59 \backslash(\mathrm{s}, 1 \mathrm{H}, \mathrm{Ar}-\mathrm{H}) \mathrm{HRMS} \backslash(\mathrm{m} / \mathrm{z}) 633.3098 \backslash(\backslash[\mathrm{M}+\mathrm{Na}]+, 30 \%)$ Analysis $\backslash$ (calculated, found for C33H43FN406) C $\backslash(64.90,64.69) \mathrm{H} \backslash(7.10,7.14) \mathrm{N} \backslash(9.17,9.22)$ Comparison with competing chiral derivatizing agents and applications The newly synthesized CDRs were found to provide better resolution $\backslash(3.41-9.09)$ in comparison to the resolution reported in the literature $\backslash($ Table-2). The retention times were greatly reduced $\backslash(2-6 \mathrm{~min}$, at a flow rate of $1 \mathrm{~mL} \mathrm{~min}-1)$ for the diastereomers synthesized with CDR-1 and CDR-2 as compared to those reported in literature. Thus, the developed method reduced significantly $\backslash$ (approximately 10-15 times) the consumption of organic mobile phase. The efficiency of CDR-1 and CDR-2 for diastereomeric separation and enantioselectivity was found to be better in terms of low retention times $\backslash(2-6 \mathrm{~min})$, high Rs $\backslash(3.14-9.09)$ and low LOD $\backslash(1.856 \mathrm{ng} \mathrm{mL}-1$ and $2.228 \mathrm{ng} \mathrm{mL}-1)$ in comparison to those reported in the literature $\backslash($ Table-1); new CDRs were found to be more stable $\backslash$ ( 5 month at 2-5 oC) as compared to CDRs based on DFDNB22, and naproxen22,31, and isothiocyanate26-28. Also, the separation factor $\backslash(a, 2.59$ and 2.39) for the diastereomers prepared with 
the CDR-1 and CDR-2 were found to be better than the diastereomers prepared with reported CDRs $\backslash$ (Table-2). Method validation Validation was performed according to $\mathrm{ICH}$ guideline4 and previous reports5-13. LOD of the order of $1.85 \mathrm{ng} \mathrm{mL}-1$ and $2.22 \mathrm{ng} \mathrm{mL}-1$, and LOQ of the order of $5.62 \mathrm{ng} \mathrm{mL}-1$ and $6.75 \mathrm{ng} \mathrm{mL}-1$, are obtained for the diastereomers of $\backslash(S)$-, and $\backslash(R)-M e l$, respectively. Validation table and data are given as 'Supplementary' information. Verification of Protocol The above mentioned protocol was applied for enantioseparation of $\backslash(\mathrm{RS})$-atenolol \(Atl). Sections of chromatograms showing separation of diastereomers of $\backslash(\mathrm{RS})$-Atl prepared with CDR-2 are shown in Fig.5. Since the protocol was successful other details are not being included in this paper. - Comparison with competing chiral derivatizing agents and applications The newly synthesized CDRs were found to provide better resolution $\backslash(3.41-9.09)$ in comparison to the resolution reported in the literature $\backslash($ Table-2). The retention times were greatly reduced $\backslash(2-6 \mathrm{~min}$, at a flow rate of $1 \mathrm{~mL} \mathrm{~min}-1)$ for the diastereomers synthesized with CDR-1 and CDR-2 as compared to those reported in literature. Thus, the developed method reduced significantly $\backslash$ (approximately 10-15 times) the consumption of organic mobile phase. The efficiency of CDR-1 and CDR2 for diastereomeric separation and enantioselectivity was found to be better in terms of low retention times $\backslash(2-6 \mathrm{~min})$, high Rs $\backslash(3.14-9.09)$ and low LOD $\backslash(1.856 \mathrm{ng} \mathrm{mL}-1$ and $2.228 \mathrm{ng} \mathrm{mL}-1)$ in comparison to those reported in the literature $\backslash($ Table-1); new CDRs were found to be more stable $\backslash(5$ month at 2-5 oC) as compared to CDRs based on DFDNB22, and naproxen22,31, and isothiocyanate26-28. Also, the separation factor $\backslash(a, 2.59$ and 2.39) for the diastereomers prepared with the CDR-1 and CDR-2 were found to be better than the diastereomers prepared with reported CDRs $\backslash($ Table-2). Method validation Validation was performed according to ICH guideline4 and previous reports5-13. LOD of the order of 1.85 $\mathrm{ng} \mathrm{mL-1}$ and $2.22 \mathrm{ng} \mathrm{mL}-1$, and LOQ of the order of $5.62 \mathrm{ng} \mathrm{mL}-1$ and $6.75 \mathrm{ng} \mathrm{mL}-1$, are obtained for the diastereomers of $\backslash(S)$-, and $\backslash(\mathrm{R})-\mathrm{Mel}$, respectively. Validation table and data are given as 'Supplementary' information. Verification of Protocol The above mentioned protocol was applied for enantioseparation of $\backslash(\mathrm{RS})$-atenolol $\backslash(\mathrm{Atl})$. Sections of chromatograms showing separation of diastereomers of $\backslash(\mathrm{RS})$-Atl prepared with CDR-2 are shown in Fig.5. Since the protocol was successful other details are not being included in this paper.

\section{References}

REFERENCES 1. Ariëns, E.J. "Stereochemistry, a basis for sophisticated nonsense in pharmacokinetics and clinical pharmacology". Eur. J. Clin. Pharmacol $26 \backslash(6), 663-668 \backslash(1984)$. 2. Muller, G.W. Thalidomide: From Tragedy to New Drug Discover. Chemtech 27\(1) 21-25 \(1997). 3. FDA's Policy Statement for the Development of New Stereoisomeric Drugs. Chirality 4, 338-340 \(1992). 4. International conference on harmonization $\backslash(\mathrm{ICH})$ guidelines Q2B document:validation of analytical procedures, Geneva, 1996. 5. Bhushan, R. \& Martens, J. Amino Acids: Chromatographic Separation and Enantioresolution. HNB Publishing, New York, 2010. 6. Bhushan, R. \& Tanwar, S. Synthesis of succinimidyI-I(S)-naproxen ester and its application for indirect enantioresolution of penicillamine by reversed-phase high-performance liquid chromatography. J. Chromatogr. A 1209, 174-178 \(2008). 7. Bhushan, R. \& Dubey, R. Synthesis of $\backslash(S)$-naproxen-benzotriazole and its application as chiral derivatizing reagent for microwave-assisted synthesis and indirect high performance liquid 
chromatographic separation of diastereomers of penicillamine, cysteine and homocysteine. J. Chromatogr. A 1218, 3648-3653 \(2011). 8. Bhushan, R., Tanwar, S. \& Dixit, S. Indirect enantioresolution of $\backslash(R, S)$-mexiletine by reversed-phase high performance liquid chromatography via diastereomerization with $\backslash \backslash \backslash(S, S)$-0,0'-di-p-toluoyl tartaric acid anhydride], \(S)-naproxen and nine chiral reagents synthesized as variants of Marfey's reagent. Biomed. Chromatogr. 25, 398-404 \(2011). 9. Bhushan, R. \& Nagar, H. Indirect enantioseparation of proteinogenic amino acids using naproxen-based chiral derivatizing reagent and HPLC. Biomed. Chromatogr. 27, 750-756 \(2013). 10. Bhushan, R. \& Nagar, H. Indirect enantioseparation of selenomethionine by reversed-phase high performance liquid chromatography using a newly synthesized chiral derivatizing reagent based on $\backslash(\mathrm{S})$-naproxen moiety. Biomed. Chromatogr. 28, 106-111 \(2014). 11. Batra, S. \& Bhushan, R. Liquid chromatographic enantioseparation of $\backslash(R S)$-mexiletine and $\backslash(R S)$-fluoxetine using chiral derivatizing reagents synthesized with $\backslash(\mathrm{S})$-naproxen moiety. Biomed. Chromatogr. 28, 815-825 \(2014). 12. Singh, M. \& Bhushan, R. \(S)-Naproxen based novel chiral reagent for $\mathrm{C} \square \mathrm{N}$ bond formation: enantioseparation of some $\beta$-blockers, determination of absolute configuration and elution order of diastereomers. RSC Adv. 5, 70255-70264 \(2015). 13. Vashistha, V.K. \& Bhushan, R. Chirality recognition for assessing the enantiomeric purity of betaxolol. Tetrahedron: Asymmetry 26, 304-311 \(2015). 14. Bhushan, R. \& Brückner, H. Marfey's reagent for chiral amino acid analysis: A review. Amino Acids 27, 231-247 \(2004). 15. Bhushan, R. \& Brückner, H. Use of Marfey's reagent and analogs for chiral amino acid analysis: assessment and applications to natural products and biological systems. J. Chromatogr. B 879, 3148-3161 \(2011). 16. B'Hymer, C., MontesBayon, M. \& Caruso, J.A. Marfey's reagent: past, present, and future uses of 1-fluoro-2,4-dinitrophenyl-5-Lalanine amide. J. Sep. Sci. 26, 7-19 \(2003). 17. Bhushan, R. \& Dubey, R. Synthesis of \(S)-naproxenbenzotriazole and its application as chiral derivatizing reagent for microwave-assisted synthesis and indirect high performance liquid chromatographic separation of diastereomers of penicillamine, cysteine and homocysteine. J. Chromatogr. A 1218, 3648-3653 \(2011). 18. Katritzky, A.R., Jishkariani, D. \& Narindoshvili, T. Convenient Synthesis of ibuprofen and naproxen aminoacyl, dipeptidoyl and ester derivatives. Chem. Biol. Drug Des. 73, 618-626 \(2009). 19. König, W. \& Geiger, R. N-hydroxyverbindungen als katalysatoren für die aminolyse aktivierter ester. Chemische Berichte $106 \backslash(11), 3626-3635 \backslash(1973)$. 20. Anderson, G.W., Zimmerman, J.E. \& Callahan, F.M. N-hydroxysuccinimide esters in peptide synthesis. J. Am. Chem. Soc. $85 \backslash(19), 3039 \backslash(1963)$. 21. Bhushan, R. \& Kumar, V. Indirect enantioseparation of amino acids by reversed-phase liquid chromatography using new chiral derivatizing reagents synthesized from s-triazine chloride. J. Chromatogr. A 1201, 35-42 \(2008). 22. Bhushan, R. \& Tanwar, S. Reversedphase high-performance liquid chromatographic enantioresolution of six $\beta$-blockers using dinitrophenyl-LPro N-hydroxysuccinimide ester, N-succinimidyl-\(S)-2-I(6-methoxynaphth-2-yl) propionate and twelve variants of Sanger's reagent as chiral derivatizing reagents. Biomed. Chromatogr. 23, 1291-1299 \(2009). 23. Bhushan, R. Enantiomeric Purity of Chiral Derivatizing Reagents for Enantioresolution, Bioanalysis $3 \backslash$ (18), 2057-2060 \(2011). 24. Dalgliesh, C.E. The optical resolution of aromatic amino acids on paper chromatograms. J. Chem. Soc. 137, 3940-3942 \(1952). 25. Bhushan, R. \& Dixit, S. Enantioresolution of five $\beta$-blockers by reversed-phase high-performance liquid chromatography using fifteen chiral derivatizing reagents having amino acids or their amides as chiral auxiliaries on a cyanuric chloride platform. Biomed. Chromatogr. 26, 239-246 \(2012). 26. Kleidernigg, O.P., Posch, K. \& Lindner, W. 
Synthesis and application of a new isothiocyanate as a chiral derivatizing agent for the indirect resolution of chiral amino alcohols and amines. J. Chromatogr. A 729, 33-42 \(1996). 27. Büschges, R., Linde, H., Mutschler, E. \& Spahn-Langguth, H. Chloroformates and isothiocyanates derived from 2arylpropionic acids as chiral reagents: synthetic routes and chromatographic behaviour of the derivatives. J. Chromatogr. A 725, 323-334 \(1996). 28. Péter, M., Gyéresi, A. \& Fülöp, F. Liquid chromatographic

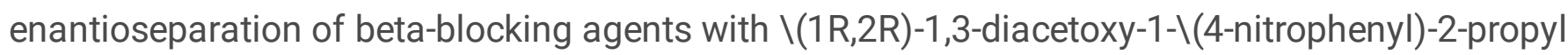
isothiocyanate as chiral derivatizing agent. J. Chromatogr. A 910\(2), 247-253 \(2001). 29. Ko, M.Y., Shin, D.H., Oh, J.W., Asegahegn, W.S. \& Kim, K.H. Chiral separation of beta-blockers after derivatization with a new chiral derivatization agent, GATC. Arch Pharm Res. 29\(11), 1061-1065 \(2006). 30. Bhushan, R. \& Nagar, H. Enantioseparation of orciprenaline, betaxolol and propranolol using HPLC and new chiral reagents based on 1,5-difluoro-2,4-dinitrobenzene. Analytical Letters 47, 202-219 \(2014). 31. Péter, M. \& Fülöp, F. Comparison of isothiocyanate chiral derivatizing reagents for high-performance liquid chromatography. Chromatographia. 56, 631-636 \(2002).

\section{Acknowledgements}

ACKNOWLEGMENTS Authors are grateful to the University Grants Commission of India \(UGC), New Delhi, for the award of a senior research fellowship \(to S.A.).

\section{Figures}

\section{Figure 1}

Captions Captions for Figures and Tables

\section{Supplementary Files}

This is a list of supplementary files associated with this preprint. Click to download.

- supplement0.docx

- supplement0.docx 